OPEN ACCESS

Edited by:

Christoph Becker,

University of Erlangen-Nuremberg,

Germany

Reviewed by:

Silvia D'Alessio,

Humanitas Università, Italy

Andreas Diefenbach,

Charité Universitätsmedizin

Berlin, Germany

Claudio Nicoletti,

University of Florence, Italy

*Correspondence:

Hiroshi Kiyono

kiyono@ims.u-tokyo.ac.jp

Specialty section:

This article was submitted

to Mucosal Immunity,

a section of the journal

Frontiers in Immunology

Received: 26 July 2017 Accepted: 29 November 2017 Published: 13 December 2017

Citation:

Kurashima Y, Yamamoto D, Nelson $S$, Uematsu S, Ernst PB, Nakayama T and Kiyono H (2017) Mucosal

Mesenchymal Cells: Secondary Barrier and Peripheral Educator for the Gut Immune System.

Front. Immunol. 8:1787. doi: 10.3389/fimmu.2017.01787

\section{Mucosal Mesenchymal Cells: Secondary Barrier and Peripheral Educator for the Gut Immune System}

\author{
Yosuke Kurashima ${ }^{1,2,3,4,5,6}$, Daiki Yamamoto', Sean Nelson', Satoshi Uematsu ${ }^{4,6,7}$, \\ Peter B. Ernst ${ }^{6,8,9}$, Toshinori Nakayama ${ }^{3,6,10}$ and Hiroshi Kiyono ${ }^{1,2,6,10 *}$
}

${ }^{1}$ Division of Mucosal Immunology, Department of Microbiology and Immunology, The Institute of Medical Science, The University of Tokyo, Tokyo, Japan, ${ }^{2}$ Division of Clinical Vaccinology, International Research and Development Center for Mucosal Vaccines, The Institute of Medical Science, The University of Tokyo, Tokyo, Japan, ${ }^{3}$ Institute for Global Prominent Research, Chiba University, Chiba, Japan, ${ }^{4}$ Department of Mucosal Immunology, Graduate School of Medicine, Chiba University, Chiba, Japan, ${ }^{5}$ Department of Innovative Medicine, Graduate School of Medicine, Chiba University, Chiba, Japan, ${ }^{6}$ Chiba University-UC San Diego Center for Mucosal Immunology, Allergy, and Vaccines (CU-UCSD cMAV), San Diego, CA, Unites States, ${ }^{7}$ Division of Innate Immune Regulation, International Research and Development Center for Mucosal Vaccines, The Institute of Medical Science, The University of Tokyo, Tokyo, Japan, ${ }^{8}$ Center for Veterinary Sciences and Comparative Medicine, University of California, San Diego, CA, Unites States, ${ }^{9}$ Division of Comparative Pathology and Medicine, Department of Pathology, University of California, San Diego, CA, Unites States, ${ }^{10}$ Department of Immunology, Graduate School of Medicine, Chiba University, Chiba, Japan

Stromal connective tissue contains mesenchymal cells, including fibroblasts and myofibroblasts, which line the tissue structure. However, it has been identified that the function of mesenchymal cells is not just structural - they also play critical roles in the creation and regulation of intestinal homeostasis. Thus, mucosal mesenchymal cells instruct intestinal immune cell education (or peripheral immune education) and epithelial cell differentiation thereby shaping the local environment of the mucosal immune system. Malfunction of the mesenchymal cell-mediated instruction system (e.g., fibrosis) leads to pathological conditions such as intestinal stricture.

Keywords: intestinal stem cells, peripheral education, fibroblasts, mucosal healing, mesenchymal cells

\section{INTRODUCTION}

Occurring below the mucosal mucus and membrane layer and at the forefront of host-environmental encounters, interactions between epithelial and immune cells are indispensable for the formation of the chemical, physical, and immunological barriers of the mucosal epithelium. Such interactions lead to immunophysiological functions-secretion of mucus containing anti-microbial peptides and secretory IgA antibodies, and enhancement of tight junctions-ultimately promoting intestinal homeostasis (1). These indispensable roles of the mucosal epithelial-immune cell barrier are well known due to functional studies demonstrating that disruption of barrier-associated genes (e.g., encoding MUC2 and E-cadherin) results in intestinal inflammation (2-4). Recently, however, focus has shifted toward the role of mesenchymal cell interactions with epithelial and immune cells and their effect on the formation and maintenance of intestinal homeostasis.

Mesenchymal cells are a large heterogenous population that includes fibroblasts, myofibroblasts, interstitial cells of Cajal, pericytes, many of which are within the mucosa (5). They are negative for common molecular markers for epithelial and hematopoietic cells (e.g., E-cadherin and CD45, respectively) but are positive for a combination of vimentin, CD90 (also known as THY1), S100A4, $\alpha$-smooth muscle actin, desmin, smoothelin, platelet-derived growth factor (PDGF) receptor, and 
c-kit $(6,7)$ (Table 1). Most notably, the expression of $\alpha$-smooth muscle actin is used to distinguish between fibroblasts and myofibroblasts as the negative and positive cells, respectively [Table 1; (5)].

Although mesenchymal cells have various origins, they provide mechanical and structural support functions that are integral to intestinal morphogenesis, organogenesis, and homeostasis (8-10). In mice lacking PDGF, a necessary mesenchymal growth factor (8), intestinal myofibroblasts (pericryptal fibroblasts) are lost in the villous crypts during intestinal formation, leading to disorganization of the intestine (8). In organogenesis of lymph nodes [e.g., in Peyer's patches (PPs) and mesenteric lymph nodes], mesenchymal cells termed lymphoid tissue organizer aid in the accumulation of lymphocytes through stimulation by lymphoid tissue inducer cells (LTi or Group 3 innate lymphoid cells) $(9,10)$. Therefore, mesenchymal cells play multiple essential roles in developing and preserving gut anatomical homeostasis. In addition, interstitial cells of Cajal regulate gastrointestinal motility: loss of these through mutations of KIT cause abnormalities in intestinal peristalsis (5). Pericytes, or parietal cells, surround capillary vessels where they are responsible for regulating stretching and vascular permeability, and perform angiogenesis through interactions with endothelial cells, as reviewed elsewhere $(5,11)$. Fibroblasts and myofibroblasts, the main topic of this review, are essential for the formation of the higher-order structure of tissue (e.g., gastrointestinal tract) through production of extracellular matrix (ECM) (12), and therefore play an indispensable role in tissue regeneration and restoration (12).

In recent years, it has become apparent that mesenchymal cells act on various immunocompetent cells, such as dendritic cells and mast cells, to modulate differentiation, proliferation, and the function of these cells in peripheral tissues in a process we term "peripheral education" (13-15). Furthermore, mesenchymal cells regulate epithelial lineage development in intestinal infection (16). In colonic mucosa, the CD90-positive mesenchymal cell population expressing toll-like receptors and Nod-like receptors possesses phagocytic and antigen-presenting capabilities (17). Although their antigen-presenting capabilities are not as great as those of professional antigen-presenting cells, it is suggested that mesenchymal cells are involved in the direct induction or enhancement of mucosal acquired immune responses (17). Here, we provide an overview of recent advances concerning the role of mesenchymal cells in peripheral education and epithelial membrane repair for the creation of a healthy gut immune environment.

\section{MESENCHYMAL REGULATORY SYSTEM FOR MUCOSAL FRONTLINE}

\section{Function of Mucosal Mesenchymal System in Epithelial Differentiation}

Along the gut epithelial layer, which forms the first line of mucosal barrier by producing mucus containing antibacterial substances (1), microfold cells ( $M$ cells) are a gateway for the outside environment and are responsible for antigen uptake (or sampling) from the mucosal lumen (18). M cells are primarily located in the follicle-associated epithelium of PPs, a major organized lymphoid structure for the induction and regulation of the appropriate antigen-specific mucosal immune responses that confer protection and commensalism against pathogenic and beneficial antigens, respectively $(9,18)$. In vivo studies and in vitro organoid studies have shown that the cytokine RANKL (also known as TNFSF11) is essential for the induction of differentiation and maintenance of $\mathrm{M}$ cells located in the follicleassociated epithelium of PPs $(19,20)$. Mesenchymal cells located just below the follicle-associated epithelium are the main source of RANKL (19). A most recent study has shown that the unique type 6 collagen expressing mesenchymal cell populations producing RANKL are involved in the development of M cells (21). $M$ cells are an entry site of antigens and luminal bacteria and antigen presentations were subsequently occurred for generating IgA in the PPs; therefore, RANKL induced $\mathrm{M}$ cell differentiation is imperative to the maintenance of host-microbe symbiosis (21). This type of mesenchymal instruction system for the development of mucosal immune system via the $\mathrm{M}$ cell induction is one of examples for the essential role of mesenchymal cell family for mucosal frontline upkeeping system $(19,20)$.

In the villi, mesenchymal cells guide epithelial cell (EC) lineage differentiation in both physiological and pathological conditions $(6,22)$. Under the homeostatic condition, epithelial stem cells primarily differentiate into absorptive ECs, which perform the primary physiological function of the gastrointestinal tract (1), however, upon infection, epithelial stem cells shift toward secretory EC differentiation (23). In the case of

TABLE 1 | Characteristics of surface molecules expressed by different mesenchymal cells.

\begin{tabular}{|c|c|c|c|c|c|}
\hline & Fibroblasts & Myofibroblasts & Pericytes & Smooth muscle & Interstitial cells of Cajal \\
\hline Vimentin & + & + & + & - & + \\
\hline CD90 & + & + & \pm & - & - \\
\hline S100A4 & + & + & - & - & - \\
\hline Alpha-smooth muscle actin & - & + & + & + & - \\
\hline Desmin & - & - & + & + & - \\
\hline Smoothelin & - & - & + & + & - \\
\hline Platelet-derived growth factor receptor & + & + & + & + & $?$ \\
\hline c-kit & - & - & - & - & + \\
\hline
\end{tabular}

The expression molecules of mesenchymal cells (e.g., fibroblasts, myofibroblasts, pericytes, smooth muscle cells, and interstitial cells of Cajal) were defined.

aThe table was prepared by the data described in Ref. $(6,7)$. 
bacterial (e.g., Salmonella) infection, rapid differentiation and proliferation of secretory ECs such as Paneth cells (which secrete anti-microbial peptides, such as defensin and lysozyme) and goblet cells [which secrete mucin and anti-microbial proteins, such as TFF3 and resistin like $\beta$ (RELM $\beta$ ) (also known as FIZZ1)] is accelerated to clear the pathogens (23). This countermeasure shift in epithelial stem cell differentiation is mediated by pericryptal fibroblast-produced interleukin (IL)-33 (23) (Figure 1). Differentiation into secretory ECs is ordinarily repressed by Hes1 through the Notch signaling pathway $(24,25)$. But in the in vitro assessment with intestinal organoids IL-33 acts on epithelial stem cells via its receptor ST2, to suppress Notch signaling and thereby activate secretory EC differentiation (23) (Figure 1). IL-1 $\beta$, IL-6, tumor necrosis factor (TNF)- $\alpha$ and bacterial cell components (e.g., lipopolysaccharide) are involved in the stimulation of IL-33 (23), but the extent of each of their roles is still unknown and needs further investigation.

Homeostatic maintenance of epithelial stem cells is generally understood to be maintained by neighboring Paneth cell production of Wnt3, Wnt5, and EGF (26). However, in the colon where Paneth cells are lacking, mesenchymal cell production of Wnt $2 \mathrm{~b}$ works to maintain epithelial stem cells (27). In addition, mesenchymal cells are responsible for secreting Wnt-activating growth factors such as R-spondin 3 during both homeostatic and nonhomeostatic conditions $(28,29)$. A recent study indicates that, during inflammation, CD $34^{+}$fibroblasts produce niche factors, including Wnt2b, Gremlin 1, and R-spondin 1, for maintenance of the intestinal stem cell niche (29) (Figure 1). The important role of mesenchymal cells in epithelial stem cell maintenance deepens their integral role in EC differentiation. These findings imply that the function of mesenchymal cells differs among location and reflects the surrounded tissues or microenvironments.

\section{Mucosal Repair}

The intestinal mucosa is frequently threatened by environmental substances (e.g., pathogenic microorganisms, and chemicals such as alcohol) or dysbiosis of commensal microorganisms. The gut is thus equipped with multiple innate and acquired defense mechanisms (e.g., mucus, anti-microbial peptides, IgA antibodies, and Th17 cells) (30). Although these systems are essential for host protection, they concurrently cause mucosal damage, and it is therefore crucial to simultaneously initiate the mucosal tissue repairing cascade (1), which involves various factors promoting epithelial restitution followed by epithelial regeneration and differentiation (31).

Epithelial restitution occurs early on in mucosal epithelial tissue that has suffered tissue damage due to inflammatory diseases $(32,33)$. ECs near the damaged region lose polarity and migrate rapidly to the epithelial-deficient region, restoring the epithelial layer (32). Epithelial restitution does not appear to involve proliferation of ECs from the crypt region $(1,32)$; rather the process occurs through covering or sealing of the denuded area by migrating ECs (33). IL-22 has been shown to promote myofibroblast mediated epithelial repair and defense as well as epithelial stem cell protection during inflammatory bowel diseases $(34,35)$. Upon inflammation, helper T cells and innate lymphoid cells near the site of inflammation secrete IL-22 (36). IL-22 then activates NF- $\mathrm{KB}$ and AP-1 transcription factors as well as MAP kinases of myofibroblasts $(34,35)$. IL-22 activated myofibroblasts

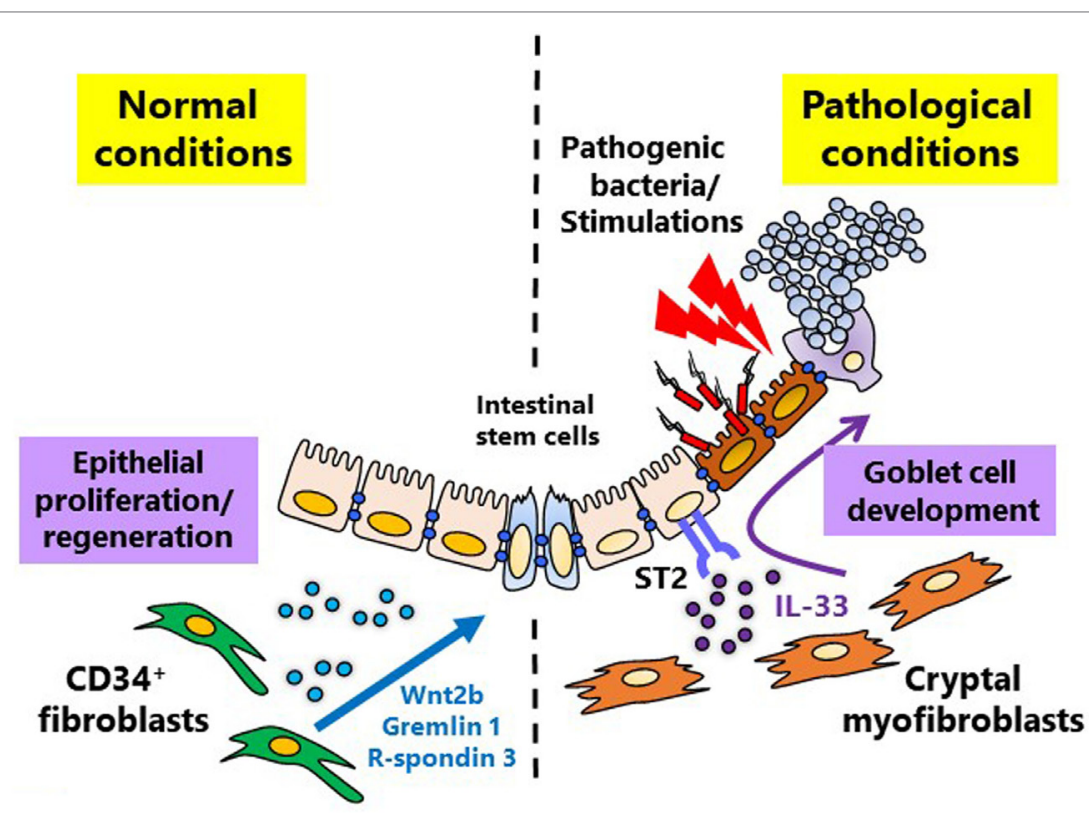

FIGURE 1 | Mesenchymal cell-instructed intestinal homeostatic and pathological conditions. Under normal conditions, mesenchymal cells promote mucosal homeostasis by maintaining physiological differentiation of absorptive epithelial cells from intestinal stem cells through the production of intestinal stem cell niche factors, including Wnt2b, Gremlin 1, and R-spondin 3. During pathological conditions, including inflammation and infection, mesenchymal cells can promote the essential switch from absorptive to secretory epithelial differentiation which is mediated by interleukin-33. 
subsequently secreted proinflammatory cytokines (e.g., IL-6, IL-8, and IL-11) as well as MMP-1 and MMP-3 imperative to repair and remodeling (34). The IL-22 induced proinflammatory cytokines are necessary for the protection of epithelial stem cells and lack thereof has been linked to intestinal pathology and loss of epithelial barrier function (35). Additionally, chemokines (e.g., CXCL12) (37), and various other cytokines [e.g., IL-6 and transforming growth factor (TGF)- $\beta 1](38,39)$, and antimicrobial proteins (e.g., TFF3) (40) are suggested to play a role in epithelial restitution, the precise mechanism is still largely unknown. In addition, other studies have shown that during various other intestinal damages such as irradiation, Lgr5 positive cells are imperative to proper EC regeneration (41).

Alongside epithelial restitution, stimulation of fibroblasts near the inflammation site is an important process. Activation by immune cells (e.g., T cells and macrophages) and EC-produced TGF- $\beta 1$ induces differentiation of fibroblasts into myofibroblasts expressing smooth muscle $\alpha$-actin ( $\alpha$ SMA) (6). Myofibroblasts specialize in the production of ECM molecules such as collagen and tenascin $\mathrm{C}$, and together with fibroblasts, promote mucosal repair by appropriately adjusting the production and degradation of the ECM $(42,43)$. In addition, myofibroblasts produce growth factors (e.g., HGF), which induce EC proliferation, leading to migration of ECs to the repair site using ECM as a scaffold (44). Because efficient induction of myofibroblasts is essential for mucosal repair, several induction mechanisms exist other than development from activated conventional fibroblasts. For instance, differentiation from ECs (epithelial-mesenchyme transition) and endothelial cells (endothelial-mesenchyme transition) have been characterized in different tissues (e.g., kidney) $(5,45-47)$. Both epithelial- and endothelial-mesenchyme transitions induce migratory fibroblastic cells expressing vimentin and $\alpha \mathrm{SMA}(5,46)$. These processes are regulated by various cytokines, including TGF- $\beta 1, \mathrm{TNF}-\alpha$, and IL- $1 \beta$ produced by immune cells and ECs (45).

In mucosal repair upon inflammatory bowel diseases (e.g., Crohn's disease), FGF2 and IL-17 produced from regulatory T cells and Th17 cells, respectively, as the result of stimulatory signals caused by dysbiosis of the intestinal flora have been shown to play a critical role (48). FGF2 and IL-17 synergistically promote expression of genes involved in intestinal mucosa healing (e.g., those encoding SPRR2, IL-6, and Arg2). IL-17 also strongly influences ECs and mesenchymal cells during the tissue disruption and healing process mentioned above (48).

Transforming growth factor- $\beta 1$ is an essential cytokine for wound healing and enhancement of ECM production (49). It has been recently announced to be discontinued the phase III trial; however, patients with Crohn's disease have been treated with antisense oligonucleotides against SMAD7, which binds to the TGF- $\beta$ receptor, blocking TGF- $\beta 1$ signaling; inhibition of SMAD7 promotes TGF- $\beta$-induced activation of SMAD2 and SMAD3 signal transducers (50), thereby activating TGF- $\beta 1$ mediated anti-inflammatory activities (50). However, chronic production of TGF- $\beta 1$ continuously activates mesenchymal cells, especially fibroblasts and myofibroblasts, leading to organ fibrosis $(51,52)$. Fibrosis causes intestinal stricture and obstruction, and repeated intestinal resection results in short bowel syndrome (53).
Although the mechanism of fibrosis induction is not fully understood and complex, excessive activation of the TGF- $\beta 1$ pathway is generally considered to be a central causative element (54). Many patients with Crohn's disease undergo surgery to relieve fibrotic complications as their disease worsens $(51,52)$. Temporal and spatial activation of TGF- $\beta 1$ is believed to lead to the wound healing; however, sudden wound healing may progress intestinal obstruction (53). Further analysis of mesenchymal cells provides promising strategies for the control of wound healing.

\section{MUCOSAL PERIPHERAL EDUCATION}

\section{Mucosal Dendritic Cell Education}

The intestinal tract is a special tissue that is constantly in contact with various stimuli such as microflora, foods, and metabolites. Since the intestinal tract acts as a gateway for environmental antigens and pathogenic microorganisms, the mucosal immune system must achieve the appropriate immunological balance between active and quiescent responses. The qualitative and quantitative adjustment of intestinal IgA antibody production is deeply involved in both the protection against pathogenic bacterial infection and the maintenance of the appropriate composition of commensal bacterial flora for a healthy gut environment (55). In steady state, secretary IgA antibodies are required to maintain healthy bacterial species, so called commensal mutualism (56) (Figure 2). Disruption of the mucosal immune system-mediated balancing act leads to the onset of various acute and chronic inflammatory diseases (57). In the induction of mucosal IgA antibody production, intestinal dendritic cells play a critical role by synthesizing retinoic acid (RA), which promotes antigen-specific mucosal $\mathrm{T}$ and $\mathrm{B}$ lymphocyte responses; this role is in addition to the classical role of dendritic cells in antigen presentation to $\mathrm{T}$ and $\mathrm{B}$ lymphocytes in organized inductive tissue (e.g., PPs) (58). RA-induced lymphocytes express gut-imprinting molecules such as the chemokine receptor CCR9 and the integrin $\alpha 4 \beta 7$, which are necessary for the preferential migration of antigen-specific lymphocytes from PPs to the lamina propria regions of intestinal tract where they produce IgA (59). RA production is peculiar to "mucosal-type" dendritic cells located in mucosa-associated lymphoid tissues (e.g., PPs), not splenic dendritic cells $(58,60)$. Furthermore, some mesenchymal cells can produce RA and GM-CSF (also known as CSF2), critical cytokine for generation of dendritic cells, in the vicinity of dendritic cells in the intestinal lamina propria (15) (Figure 2); from in vitro analysis, it has become obvious that the mesenchymal cells can convert spleen dendritic cells into "mucosal-type" dendritic cells (15). It is thus plausible to suggest the existence of a mucosal mesenchymal-dendritic cell cross-talk system that preferentially educates lymphocytes to produce IgA antibodies in the mucosa-associated tissues. Dendritic cells within the mucosal lamina propria can produce RA independently of intestinal bacteria, but RA produced from mesenchymal cells is dependent on stimulation from intestinal bacteria (15). These findings suggest that initial peripheral education machinery mediated by RA is orchestrated by the cross-communication between mesenchymal cells and commensal microbiota, which leads to the creation of a mucosal imprinting environment. 


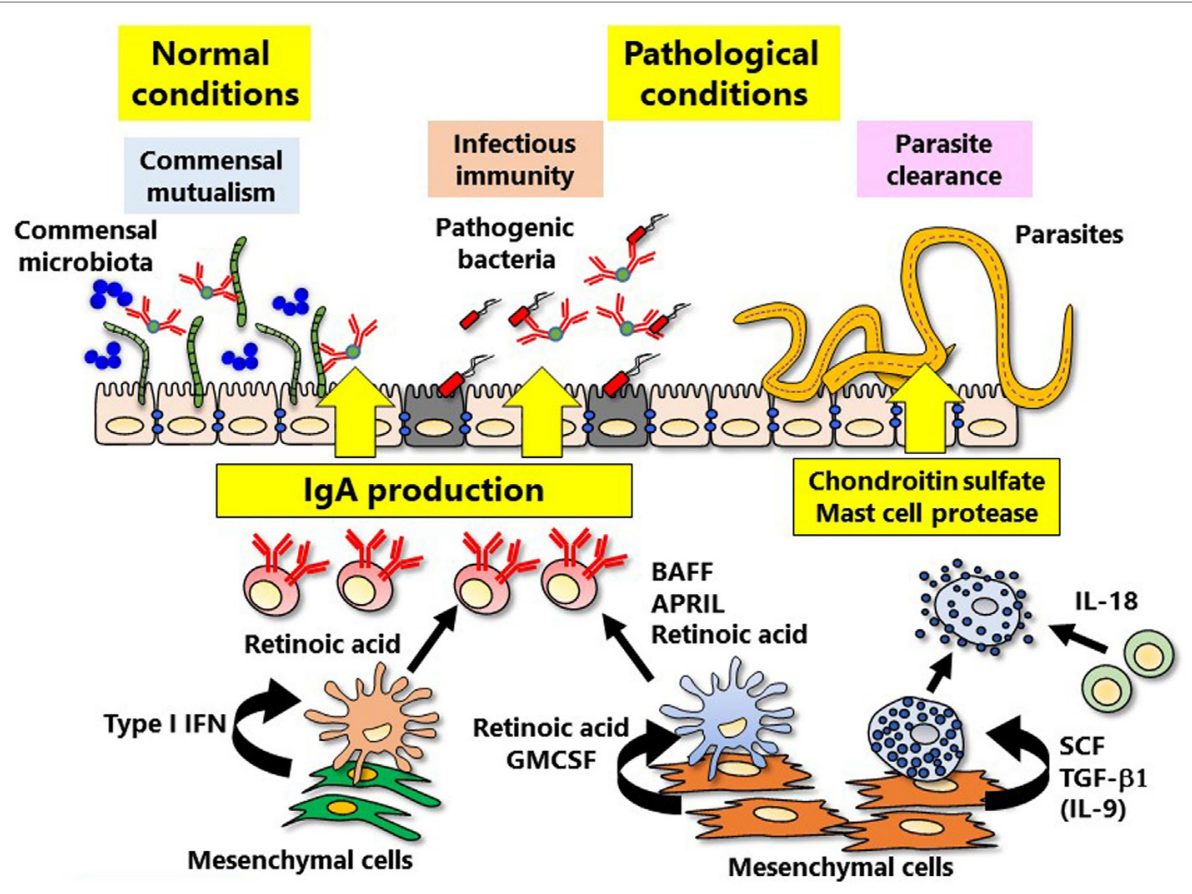

FIGURE 2 | Mesenchymal cell-instructed immune cell education. Mesenchymal cells induce peripheral immune education, thereby refining intestinal-specific immune responses. IgA is involved in the both normal (commensal mutualism) and pathological (the protection against bacterial infection) conditions. Induction of IgA is directly and indirectly regulated by mucosal mesenchymal cells via type I IFN and retinoic acid. In addition, the defense against parasite infection mediated by mast cells is also regulated by cytokines produced from mesenchymal cells.

In addition to RA, cytokines that promote IgA induction such as APRIL (also known as TNFSF13) and BAFF (also known as TNFSF13B) are produced by plasmacytoid dendritic cells, another subgroup of dendritic cells within the intestinal mucosa (61) (Figure 2). Type I IFN is deeply involved in the induction of mucosal plasmacytoid dendritic cells, and it has recently been reported that intestinal mesenchymal cells are the main source of type I IFN (61). Production of type I IFN from mesenchymal cells is stimulated by intestinal bacteria (61). It is thus necessary to further verify how and what kinds of gut bacteria and/or their derived factor(s) are involved in mucosal mesenchymal cellinstructed gut-imprinting and IgA production.

\section{Mucosal Mast Cell Education}

Mast cells undergo maturation after being distributed throughout the whole body, including gut mucosa, via blood from the bone marrow (13). The c-kit receptors on mast cells and the c-kit ligand (stem cell factor, SCF; also known as KITLG), are essential for maintaining mast cells; mice lacking either of these molecules have no mast cells (62). Mesenchymal cells, especially fibroblasts, are the main secretory source of SCF (13). The SCF-c-kit pathway works together with prostaglandin D2 and its receptor (DP1) pathway in the maturation of mast cells, including granule formation (63). Mast cell granules containing chondroitin sulfate and proteases (e.g., the chymase Mcpt1) are involved in the control of parasitic infections (64-66). In mice infected with an intestinal helminth, antigen-IgE complex and IL-18 activated mucosal mast cells to release chondroitin sulfate and Mcpt1 to achieve parasite expulsion. Chondroitin sulfate and Mcpt 1 caused direct parasite damage and inhibited parasite invasion of ECs (67). However, inappropriate and unnecessary activation of mast cells within the mucosa, inflammation, and allergic reaction took place. For instance, proteases released from mast cells accelerate the influx of inflammatory cells (e.g., neutrophils) into the inflammatory site by weakening the tight junctions of endothelial cells (68).

Mast cells are classified into two subsets: "connective tissue type" and "mucosal type" (13). Mast cells that have heparincontaining granules are common in connective tissue, whereas those with chondroitin sulfate-containing granules are preferentially found in the intestine (13). In mast cells associated with the mucosal surface, expression of proteases Mcpt1 and -2 is particularly elevated (69). For the generation of "mucosaltype" mast cells, not only IL-9 producing T cells (so-called Th9 cells), but also gut mesenchymal cells have been shown to play a critical role (14). In vitro expression of heparin-Mcpt4 or chondroitin sulfate-Mcpt1 (representing "connective tissue type" or "mucosal type," respectively) is induced by co-culturing bone marrow-derived mast cell precursors with mesenchymal cells from skin dermis or intestinal mucosa, respectively (14). Because expression of Mcpt1 is induced by TGF- $\beta 1$ and IL- 9 (70), only intestinal, but not skin mesenchymal cells, were able to induce Mcpt1 expression (71) (Figure 2). Taken together, these results demonstrate the presence of an intestinal mesenchymal cell-instructed "mucosal-type" mast cell development system. Further, it is interesting to hypothesize that the mesenchymal 
cells at different tissue locations (e.g., skin and gut) adopting the biological and anatomical characteristics of respective tissues are a major educator for the generation of "connective tissue type" and "mucosal-type" mast cells.

In summary, our new and advanced knowledge of the role of mesenchymal cell-instructed functional maturation of immunocompetent cells (e.g., dendritic cells and mast cells) will allow us to create novel strategies for the control of mucosal infection and inflammation in the near future.

\section{FUTURE PERSPECTIVES}

The functions of mucosal mesenchymal cells as the peripheral educator of immunological cells are critical in the development and maintenance of the intestinal homeostatic condition. Disruption of mucosal mesenchymal cell-instructed peripheral education system is likely a cause of gut pathological conditions. However, only a portion of the physiological, immunological, and pathological roles of these cells is clear, and detailed molecular and cellular mechanisms of the mucosal mesenchymal cell-instructed peripheral education system have yet to be elucidated.

Since mesenchymal cells are composed of a heterogeneous cell population, including fibroblasts, myofibroblasts, pericytes, interstitial cells of Cajal, adipocytes, and others, there remains a problem regarding the correct classification of subpopulations with specific molecular and morphological identification factors. Further investigations of the molecular role of mesenchymal cells in immune peripheral education, mucosal barrier formation, and fibrosis are required. It is thus important to elucidate

\section{REFERENCES}

1. Kurashima Y, Kiyono H. Mucosal ecological network of epithelium and immune cells for gut homeostasis and tissue healing. Annu Rev Immunol (2017) 35:119-47. doi:10.1146/annurev-immunol-051116-052424

2. Van der Sluis M, De Koning BA, De Bruijn AC, Velcich A, Meijerink JP, Van Goudoever JB, et al. Muc2-deficient mice spontaneously develop colitis, indicating that MUC2 is critical for colonic protection. Gastroenterology (2006) 131:117-29. doi:10.1053/j.gastro.2006.04.020

3. UK IBD Genetics Consortium, Barrett JC, Lee JC, Lees CW, Prescott NJ, Anderson CA, et al. Genome-wide association study of ulcerative colitis identifies three new susceptibility loci, including the HNF4A region. Nat Genet (2009) 41:1330-4. doi:10.1038/ng.483

4. Grill JI, Neumann J, Hiltwein F, Kolligs FT, Schneider MR. Intestinal E-cadherin deficiency aggravates dextran sodium sulfate-induced colitis. Dig Dis Sci (2015) 60:895-902. doi:10.1007/s10620-015-3551-x

5. Powell DW, Pinchuk IV, Saada JI, Chen X, Mifflin RC. Mesenchymal cells of the intestinal lamina propria. Annu Rev Physiol (2011) 73:213-37. doi:10.1146/ annurev.physiol.70.113006.100646

6. Roulis M, Flavell RA. Fibroblasts and myofibroblasts of the intestinal lamina propria in physiology and disease. Differentiation (2016) 92:116-31. doi:10.1016/j.diff.2016.05.002

7. Koliaraki V, Pallangyo CK, Greten FR, Kollias G. Mesenchymal cells in colon cancer. Gastroenterology (2017) 152:964-79. doi:10.1053/j.gastro.2016.11.049

8. Karlsson L, Lindahl P, Heath JK, Betsholtz C. Abnormal gastrointestinal development in PDGF-A and PDGFR-(alpha) deficient mice implicates a novel mesenchymal structure with putative instructive properties in villus morphogenesis. Development (2000) 127:3457-66.

9. Kiyono H, Fukuyama S. NALT- versus Peyer's-patch-mediated mucosal immunity. Nat Rev Immunol (2004) 4:699-710. doi:10.1038/nri1439

10. Bar-Ephraim YE, Mebius RE. Innate lymphoid cells in secondary lymphoid organs. Immunol Rev (2016) 271:185-99. doi:10.1111/imr.12407 the precise molecular interaction(s) between mesenchymal cells and immune cells to understand the bidirectional regulatory mechanisms. To this end, our current and future efforts aim to clarify the novel regulatory function of mesenchymal cells in the prevention of excess inflammatory reactions.

\section{AUTHOR CONTRIBUTIONS}

YK, DY, NS, SU, PE, TN, and HK conceived and wrote the manuscript.

\section{ACKNOWLEDGMENTS}

We appreciate our colleagues (S. Matsumura, A. Inami, S. Murasaki, and Y. Kogure), and former and current collaborators, who have shared their expertise of each component of the mucosal immunology. This work was supported by grants from The Ministry of Education, Culture, Sports, Science, and Technology; Translational Research Network Program (at the University of Tokyo) Seeds A (YK), B (HK), and C (HK); Leading Initiative for Excellent Young Researchers (LEADER) (YK) Japan Agency for Medical Research and Development (HK); Japan Society for the Promotion of Science; Grant-in Aid for Scientific Research S (HK; 23229004); Grant-in-Aid for Young Scientists (A) (YK; 16H06243); Challenging Exploratory Research (YK; 17K19550); Senri Life Science Foundation (YK); and Mochida Memorial Foundation for Medical and Pharmaceutical Research (YK) and the Chiba University-UC San Diego Center for Mucosal Immunology, Allergy, and Vaccines (PE and $\mathrm{HK}$ ).

11. Mifflin RC, Pinchuk IV, Saada JI, Powell DW. Intestinal myofibroblasts: targets for stem cell therapy. Am J Physiol Gastrointest Liver Physiol (2011) 300:G684-96. doi:10.1152/ajpgi.00474.2010

12. Klingberg F, Hinz B, White ES. The myofibroblast matrix: implications for tissue repair and fibrosis. J Pathol (2013) 229:298-309. doi:10.1002/path.4104

13. Gurish MF, Austen KF. Developmental origin and functional specialization of mast cell subsets. Immunity (2012) 37:25-33. doi:10.1016/j.immuni.2012. 07.003

14. Kurashima Y, Amiya T, Fujisawa K, Shibata N, Suzuki Y, Kogure Y, et al. The enzyme Cyp26b1 mediates inhibition of mast cell activation by fibroblasts to maintain skin-barrier homeostasis. Immunity (2014) 40:530-41. doi:10.1016/j.immuni.2014.01.014

15. Vicente-Suarez I, Larange A, Reardon C, Matho M, Feau S, Chodaczek G, et al. Unique lamina propria stromal cells imprint the functional phenotype of mucosal dendritic cells. Mucosal Immunol (2015) 8:141-51. doi:10.1038/ mi.2014.51

16. Valenta T, Degirmenci B, Moor AE, Herr P, Zimmerli D, Moor MB, et al. Wnt ligands secreted by subepithelial mesenchymal cells are essential for the survival of intestinal stem cells and gut homeostasis. Cell Rep (2016) 15:911-8. doi:10.1016/j.celrep.2016.03.088

17. Owens BM, Steevels TA, Dudek M, Walcott D, Sun MY, Mayer A, et al. CD90(+) stromal cells are non-professional innate immune effectors of the human colonic mucosa. Front Immunol (2013) 4:307. doi:10.3389/fimmu. 2013.00307

18. Ohno H. Intestinal M cells. J Biochem (2016) 159:151-60. doi:10.1093/jb/ mvv121

19. Knoop KA, Kumar N, Butler BR, Sakthivel SK, Taylor RT, Nochi T, et al. RANKL is necessary and sufficient to initiate development of antigen-sampling M cells in the intestinal epithelium. J Immunol (2009) 183:5738-47. doi:10.4049/jimmunol.0901563

20. de Lau W, Kujala P, Schneeberger K, Middendorp S, Li VS, Barker N, et al. Peyer's patch $\mathrm{M}$ cells derived from Lgr5(+) stem cells require SpiB and are 
induced by RankL in cultured "miniguts". Mol Cell Biol (2012) 32:3639-47. doi:10.1128/MCB.00434-12

21. Nagashima K, Sawa S, Nitta T, Tsutsumi M, Okamura T, Penninger JM, et al. Identification of subepithelial mesenchymal cells that induce IgA and diversify gut microbiota. Nat Immunol (2017) 18:675-82. doi:10.1038/ni.3732

22. Hinz B. Myofibroblasts. Exp Eye Res (2016) 142:56-70. doi:10.1016/j. exer.2015.07.009

23. Mahapatro M, Foersch S, Hefele M, He GW, Giner-Ventura E, Mchedlidze T, et al. Programming of intestinal epithelial differentiation by IL-33 derived from pericryptal fibroblasts in response to systemic infection. Cell Rep (2016) 15:1743-56. doi:10.1016/j.celrep.2016.04.049

24. Yang Q, Bermingham NA, Finegold MJ, Zoghbi HY. Requirement of Math1 for secretory cell lineage commitment in the mouse intestine. Science (2001) 294:2155-8. doi:10.1126/science.1065718

25. Tian H, Biehs B, Chiu C, Siebel CW, Wu Y, Costa M, et al. Opposing activities of Notch and Wnt signaling regulate intestinal stem cells and gut homeostasis. Cell Rep (2015) 11:33-42. doi:10.1016/j.celrep.2015.03.007

26. Sato T, Van Es JH, Snippert HJ, Stange DE, Vries RG, Van Den Born M, et al. Paneth cells constitute the niche for Lgr5 stem cells in intestinal crypts. Nature (2011) 469:415-8. doi:10.1038/nature09637

27. Kabiri Z, Greicius G, Madan B, Biechele S, Zhong Z, Zaribafzadeh H, et al. Stroma provides an intestinal stem cell niche in the absence of epithelial Wnts. Development (2014) 141:2206-15. doi:10.1242/dev.104976

28. Farin HF, Van Es JH, Clevers H. Redundant sources of Wnt regulate intestinal stem cells and promote formation of paneth cells. Gastroenterology (2012) 143:1518-29.e1517. doi:10.1053/j.gastro.2012.08.031

29. Stzepourginski I, Nigro G, Jacob JM, Dulauroy S, Sansonetti PJ, Eberl G, et al. CD34+ mesenchymal cells are a major component of the intestinal stem cells niche at homeostasis and after injury. Proc Natl Acad Sci U S A (2017) 114:E506-13. doi:10.1073/pnas.1620059114

30. Kurashima Y, Goto Y, Kiyono H. Mucosal innate immune cells regulate both gut homeostasis and intestinal inflammation. Eur J Immunol (2013) 43:3108-15. doi:10.1002/eji.201343782

31. Goke M, Podolsky DK. Regulation of the mucosal epithelial barrier. Baillieres Clin Gastroenterol (1996) 10:393-405. doi:10.1016/S0950-3528(96)90049-4

32. Sturm A, Dignass AU. Epithelial restitution and wound healing in inflammatory bowel disease. World J Gastroenterol (2008) 14:348-53. doi:10.3748/ wjg. 14.348

33. Neurath MF. New targets for mucosal healing and therapy in inflammatory bowel diseases. Mucosal Immunol (2014) 7:6-19. doi:10.1038/mi.2013.73

34. Andoh A, Zhang Z, Inatomi O, Fujino S, Deguchi Y, Araki Y, et al. Interleukin-22, a member of the IL-10 subfamily, induces inflammatory responses in colonic subepithelial myofibroblasts. Gastroenterology (2005) 129:969-84. doi:10.1053/j.gastro.2005.06.071

35. Hanash AM, Dudakov JA, Hua G, O'connor MH, Young LF, Singer NV, et al. Interleukin-22 protects intestinal stem cells from immune-mediated tissue damage and regulates sensitivity to graft versus host disease. Immunity (2012) 37:339-50. doi:10.1016/j.immuni.2012.05.028

36. Zenewicz LA, Yancopoulos GD, Valenzuela DM, Murphy AJ, Stevens S, Flavell RA. Innate and adaptive interleukin-22 protects mice from inflammatory bowel disease. Immunity (2008) 29:947-57. doi:10.1016/j.immuni.2008. 11.003

37. Smith JM, Johanesen PA, Wendt MK, Binion DG, Dwinell MB. CXCL12 activation of CXCR4 regulates mucosal host defense through stimulation of epithelial cell migration and promotion of intestinal barrier integrity. Am J Physiol Gastrointest Liver Physiol (2005) 288:G316-26. doi:10.1152/ ajpgi.00208.2004

38. Dignass AU, Podolsky DK. Cytokine modulation of intestinal epithelial cell restitution: central role of transforming growth factor beta. Gastroenterology (1993) 105:1323-32. doi:10.1016/0016-5085(93)90136-Z

39. Pickert G, Neufert C, Leppkes M, Zheng Y, Wittkopf N, Warntjen M, et al. STAT3 links IL-22 signaling in intestinal epithelial cells to mucosal wound healing. J Exp Med (2009) 206:1465-72. doi:10.1084/jem.20082683

40. Goke MN, Cook JR, Kunert KS, Fini ME, Gipson IK, Podolsky DK. Trefoil peptides promote restitution of wounded corneal epithelial cells. Exp Cell Res (2001) 264:337-44. doi:10.1006/excr.2000.5116

41. Metcalfe C, Kljavin NM, Ybarra R, De Sauvage FJ. Lgr5+ stem cells are indispensable for radiation-induced intestinal regeneration. Cell Stem Cell (2014) 14:149-59. doi:10.1016/j.stem.2013.11.008
42. Ding S, Walton KL, Blue RE, Mcnaughton K, Magness ST, Lund PK. Mucosal healing and fibrosis after acute or chronic inflammation in wild type FVB-N mice and C57BL6 procollagen alphal(I)-promoter-GFP reporter mice. PLoS One (2012) 7:e42568. doi:10.1371/journal.pone.0042568

43. Islam MS, Kusakabe M, Horiguchi K, Iino S, Nakamura T, Iwanaga K, et al. PDGF and TGF-beta promote tenascin-C expression in subepithelial myofibroblasts and contribute to intestinal mucosal protection in mice. Br J Pharmacol (2014) 171:375-88. doi:10.1111/bph.12452

44. Goke M, Kanai M, Podolsky DK. Intestinal fibroblasts regulate intestinal epithelial cell proliferation via hepatocyte growth factor. Am J Physiol (1998) 274:G809-18.

45. Rieder F, Kessler SP, West GA, Bhilocha S, De La Motte C, Sadler TM, et al. Inflammation-induced endothelial-to-mesenchymal transition: a novel mechanism of intestinal fibrosis. Am J Pathol (2011) 179:2660-73. doi:10.1016/j.ajpath.2011.07.042

46. Sipos F, Galamb O. Epithelial-to-mesenchymal and mesenchymal-to-epithelial transitions in the colon. World J Gastroenterol (2012) 18:601-8. doi:10.3748/ wjg.v18.i7.601

47. Sun YB, Qu X, Caruana G, Li J. The origin of renal fibroblasts/myofibroblasts and the signals that trigger fibrosis. Differentiation (2016) 92:102-7. doi:10.1016/j.diff.2016.05.008

48. Song X, Dai D, He X, Zhu S, Yao Y, Gao H, et al. Growth factor FGF2 cooperates with interleukin-17 to repair intestinal epithelial damage. Immunity (2015) 43:488-501. doi:10.1016/j.immuni.2015.06.024

49. Poniatowski LA, Wojdasiewicz P, Gasik R, Szukiewicz D. Transforming growth factor beta family: insight into the role of growth factors in regulation of fracture healing biology and potential clinical applications. Mediators Inflamm (2015) 2015:137823. doi:10.1155/2015/137823

50. Monteleone G, Neurath MF, Ardizzone S, Di Sabatino A, Fantini MC, Castiglione F, et al. Mongersen, an oral SMAD7 antisense oligonucleotide, and Crohn's disease. N Engl JMed (2015) 372:1104-13. doi:10.1056/ NEJMoa 1407250

51. Rieder F, Brenmoehl J, Leeb S, Scholmerich J, Rogler G. Wound healing and fibrosis in intestinal disease. Gut (2007) 56:130-9. doi:10.1136/gut.2006.090456

52. Hinz B. Tissue stiffness, latent TGF-betal activation, and mechanical signal transduction: implications for the pathogenesis and treatment of fibrosis. Curr Rheumatol Rep (2009) 11:120-6. doi:10.1007/s11926-009-0017-1

53. Burke JP, Mulsow JJ, O'keane C, Docherty NG, Watson RW, O'connell PR. Fibrogenesis in Crohn's disease. Am J Gastroenterol (2007) 102:439-48. doi:10.1111/j.1572-0241.2006.01010.x

54. Meng XM, Nikolic-Paterson DJ, Lan HY. TGF-beta: the master regulator of fibrosis. Nat Rev Nephrol (2016) 12:325-38. doi:10.1038/nrneph.2016.48

55. Kawamoto S, Tran TH, Maruya M, Suzuki K, Doi Y, Tsutsui Y, et al. The inhibitory receptor PD-1 regulates IgA selection and bacterial composition in the gut. Science (2012) 336:485-9. doi:10.1126/science.1217718

56. Proietti M, Cornacchione V, Rezzonico Jost T, Romagnani A, Faliti CE, Perruzza L, et al. ATP-gated ionotropic P2X7 receptor controls follicular $\mathrm{T}$ helper cell numbers in Peyer's patches to promote host-microbiota mutualism. Immunity (2014) 41:789-801. doi:10.1016/j.immuni.2014.10.010

57. Okai S, Usui F, Ohta M, Mori H, Kurokawa K, Matsumoto S, et al. Intestinal IgA as a modulator of the gut microbiota. Gut Microbes (2017) 8(5):486-92. d oi:10.1080/19490976.2017.1310357

58. Agace WW, Persson EK. How vitamin A metabolizing dendritic cells are generated in the gut mucosa. Trends Immunol (2012) 33:42-8. doi:10.1016/j. it.2011.10.001

59. Agace WW. T-cell recruitment to the intestinal mucosa. Trends Immunol (2008) 29:514-22. doi:10.1016/j.it.2008.08.003

60. Zeng R, Bscheider M, Lahl K, Lee M, Butcher EC. Generation and transcriptional programming of intestinal dendritic cells: essential role of retinoic acid. Mucosal Immunol (2016) 9:183-93. doi:10.1038/mi.2015.50

61. Tezuka H, Abe Y, Asano J, Sato T, Liu J, Iwata M, et al. Prominent role for plasmacytoid dendritic cells in mucosal $\mathrm{T}$ cell-independent IgA induction. Immunity (2011) 34:247-57. doi:10.1016/j.immuni.2011.02.002

62. Reber LL, Marichal T, Galli SJ. New models for analyzing mast cell functions in vivo. Trends Immunol (2012) 33:613-25. doi:10.1016/j.it.2012.09.008

63. Taketomi Y, Ueno N, Kojima T, Sato H, Murase R, Yamamoto K, et al. Mast cell maturation is driven via a group III phospholipase A2-prostaglandin D2-DP1 receptor paracrine axis. Nat Immunol (2013) 14:554-63. doi:10.1038/ni.2586 
64. Onah DN, Nawa Y. Mucosal mast cell-derived chondroitin sulphate levels in and worm expulsion from FcRgamma-knockout mice following oral challenge with Strongyloides venezuelensis. J Vet Sci (2004) 5:221-6.

65. Knight PA, Brown JK, Wright SH, Thornton EM, Pate JA, Miller HR. Aberrant mucosal mast cell protease expression in the enteric epithelium of nematode-infected mice lacking the integrin alphavbeta6, a transforming growth factor-betal activator. Am J Pathol (2007) 171:1237-48. doi:10.2353/ ajpath.2007.061245

66. Stevens RL, Adachi R. Protease-proteoglycan complexes of mouse and human mast cells and importance of their beta-tryptase-heparin complexes in inflammation and innate immunity. Immunol Rev (2007) 217:155-67. doi:10.1111/j.1600-065X.2007.00525.x

67. Sasaki Y, Yoshimoto T, Maruyama H, Tegoshi T, Ohta N, Arizono N, et al. IL-18 with IL-2 protects against Strongyloides venezuelensis infection by activating mucosal mast cell-dependent type 2 innate immunity. J Exp Med (2005) 202:607-16. doi:10.1084/jem.20042202

68. Hamilton MJ, Sinnamon MJ, Lyng GD, Glickman JN, Wang X, Xing W, et al. Essential role for mast cell tryptase in acute experimental colitis. Proc Natl Acad Sci U S A (2011) 108:290-5. doi:10.1073/pnas.1005758108

69. Pejler G, Ronnberg E, Waern I, Wernersson S. Mast cell proteases: multifaceted regulators of inflammatory disease. Blood (2010) 115:4981-90. doi:10.1182/ blood-2010-01-257287
70. Townsend JM, Fallon GP, Matthews JD, Smith P, Jolin EH, Mckenzie NA IL-9-deficient mice establish fundamental roles for IL-9 in pulmonary mastocytosis and goblet cell hyperplasia but not $\mathrm{T}$ cell development. Immunity (2000) 13:573-83. doi:10.1016/S1074-7613(00)00056-X

71. Chen CY, Lee JB, Liu B, Ohta S, Wang PY, Kartashov AV, et al. Induction of interleukin-9-producing mucosal mast cells promotes susceptibility to IgE-mediated experimental food allergy. Immunity (2015) 43:788-802. doi:10.1016/j.immuni.2015.08.020

Conflict of Interest Statement: The authors are not aware of any affiliations, memberships, funding, or financial holdings that might be perceived as affecting the objectivity of this review.

Copyright (C) 2017 Kurashima, Yamamoto, Nelson, Uematsu, Ernst, Nakayama and Kiyono. This is an open-access article distributed under the terms of the Creative Commons Attribution License (CC BY). The use, distribution or reproduction in other forums is permitted, provided the original author(s) or licensor are credited and that the original publication in this journal is cited, in accordance with accepted academic practice. No use, distribution or reproduction is permitted which does not comply with these terms. 